\title{
Resumen de tesis: Dinámicas publicitarias en materia de aparatología terapéutica y farmacología: una aproximación a los mercados de Córdoba, Rosario y Buenos Aires (1912 - 1938) ${ }^{1}$
}

\author{
María Dolores Rivero \\ (CIECS-CONICET) \\ doloresriv@gmail.com
}

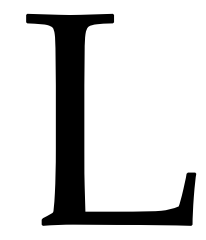

a tesis examina el proceso de configuración de tres mercados publicitarios de productos específicos orientados al mejoramiento y/o cuidado de la saluden Córdoba, Rosario y Buenos Aires entre 1912 y 1938. Centramos nuestra atención en los avisos de medicamentos e insumos médicos especializados colocados por iniciativas productoras y comercializadoras de múltiples procedencias geográficas, en las revistas emitidas por el Círculo Médico de Córdoba, el Circulo Médico de Rosario y la Asociación Médica Argentina. Dicha selección responde a que cada una de las editoriales se esgrimió como factor de socialización por excelencia de los adelantos y avatares de la ciencia médica nacional y foránea del momento.

Nuestro recorte temporal se inicia con el año en que las tres editoriales comenzarían a estar en circulación de manera simultánea, cerrando nuestro estudio en 1938; fecha en que culmina el período de entreguerras, y momento a partir del cual conjeturamos sobrevendrían nuevas lógicas en el proceso de colocación de avisos publicitarios. En este sentido, le otorgamos un lugar de particular relevancia al análisis del proceso políticoeconómico nacional de desarrollo industrial; procuramos definir distintos momentos en la constitución de los mercados especializados, concediendo un lugar significativo aunque no exclusivo- al estudio de su relación con las etapas del mencionado desarrollo de la industria argentina en general y al sector farmacéutico en particular. Convergentemente, examinamos ciertos ritmos y rasgos propios de las dinámicas de consolidación de las elites médicas de Córdoba, Rosario y Buenos Aires, considerando

\footnotetext{
${ }^{1}$ Tesis de doctorado en Historia dirigida por el Dr. Adrián Carbonetti (CIECS-CONICET y UNC) y Codirigida por el Dr. Pablo Cowen (FaHCE-UNLP); defendida el 26 de abril de 2019 en la Facultad de Humanidades y Ciencias de la Educación, Universidad Nacional de La Plata. Oficiaron como jurado: Karina Ramacciotti (UNQ-CONICET), Adriana Álvarez (UNMdP- CONICET) y Marisa Miranda (UNLPCONICET). Calificación obtenida: 10 (diez).
} 
que aquellos derroteros entramaron trayectorias institucionales y editoriales particulares en las revistas seleccionadas. Finalmente, partiendo de entender que las lógicas de producción y oferta de medicamentos e insumos médicos especializados se inscriben como parte de un conjunto de procesos propios de la modernidad -tales como la urbanización, la modernización de la agricultura, la industrialización- que terminaron por imbricarse a ciertas mudanzas de las condiciones de salud de las poblaciones, nos adentramos en los diversos y cambiantes panoramas epidemiológicos del período en las locaciones geográficas abordadas.

$\mathrm{Si}$ bien las vinculaciones entre las publicidades y el mercado de los productos especializados en salud constituyen problemáticas de escaso estudio por parte de la historiografía argentina, un conjunto de trabajos ha planteado valiosos interrogantes, abordando fuentes históricas vinculadas a estos entramados. Dichas investigaciones se han desarrollado a partir de dos líneas de trabajo. Una de ellas, representada por los estudios de Armus (2007 y 2016), Carbonetti (2013), Biernat y Simonetto (2017), los cuales ponen en perspectiva dimensiones significativas del ofrecimiento de productos medicinales en periódicos y revistas de difusión hacia fines del siglo XIX y la primera mitad del XX en la Argentina. No obstante, no podemos dejar de señalar que muchos de estos aportes restringen su interés al abordaje de aspectos socioculturales vinculados al desarrollo de enfermedades concretas, recorte que tiende a reducir el foco de estudio a una situación de crisis social y epidemiológica específica que acaba por ocupar el centro de la escena analítica.

Por otro lado, se viene desarrollando una segunda línea de trabajo -más ligada a nuestras actuales inquietudes-sugerida por Rodríguez, Carbonetti, Rizzi y Rivero (2014) y en la que Carbonetti y Sedran (2018) han contribuido recientemente, planteando que los anuncios farmacéuticos y de insumos médicos especializados constituyen elementos analíticos clave para abordar procesos históricos más complejos. En nuestra propuesta partimos de ese supuesto, procurando mostrar, a partir de casos concretos, que las publicidades son referencias empíricas privilegiadas, a partir de las cuales es posible abordar el proceso de construcción de mercados de una oferta especializada, ligada al mejoramiento y cuidado de la salud.

Nuestro corpus documental nos condujo a definir -en términos teóricos- que las publicidades constituyen dispositivos de carácter intencional dirigidos a obtener una determinada finalidad: vender un producto y abrir nuevas demandas, mediante la utilización de determinados medios dirigidos a un público específico (Caro Amela, 2008, pp. 81-82). En otras palabras, las publicidades aparecen como estrategias de mercado, entendiendo a este como un conjunto regulado de transacciones e intercambios de bienes y servicios, que trae consigo cambiantes dinámicas de competencia entre los productores y comercializadores a partir de un mecanismo de oferta y demanda, y de acuerdo al momento del desarrollo y estructuración del capitalismo.

Asimismo, entendemos que la publicidad es una actividad que carece en sí misma de esencia y que su entidad se va concretando en la medida que enactúa en un contexto o 
circunstancias concretas. En efecto, el dispositivo operacional publicitario se encuentra compuesto por un conjunto de elementos que adquieren entidad en tanto estén coordinados y relacionados entre sí: "el marco donde actúa la publicidad, el operativo semiolingüístico publicitario, la situación comunicativa publicitaria y los efectos culturales, sociales y psicosociales que se derivan de la actividad publicitaria" (Caro Amela, 2008, p. 86). En nuestro estudio ponderamos cada uno de estos elementos exceptuando el último, puesto que no tenemos acceso detallado al "universo receptor"atendiendo al hecho de que "el discurso publicitario se imbrica en el complejo sistema de discursos sociales" (Millán Barroso, 2003, p. 125), y “con ciertas condiciones de producción sociohistóricas y determinantes de las acciones y las conductas" (Marafioti, 1989, p. 98). Así, repasar la evolución histórica de las dinámicas publicitarias nos devela significativos datos que trascienden las modas o el mero acto de adquirir determinado producto, tales como la trayectoria económica de la industria nacional -especialmente la farmacológica-, los derroteros epidemiológicos de las sociedades consideradas, los procesos de profesionalización médica, etc. En relación a estos últimos, adherimos a los planteos de González Leandri (1998), referidos a que "los intentos asociativos de los médicos, junto a su pugna por la obtención de un monopolio cognitivo, formaron parte indisoluble de aquellos vastos procesos y que actuaron, a su vez, como eje de la constitución de un campo específico del arte de curar" (p. 188).

Asumir, entonces, que un acto publicitario no es solo una herramienta mercantil, sino que en las sociedades icónicas se constituye y funciona en la práctica como una de las instituciones básicas que organizan la cohesión social, derivó en la interrogación por el momento y las condiciones en que se generó. El mercado de las publicidades de medicamentos e insumos médicos especializados en los ámbitos considerados habría constituido un engranaje clave del mercado de bienes, en el que se articularían las estrategias de diversas iniciativas productoras y comercializadoras con el fin de situarse y competir. Claro que este proceso dependió del momento histórico abordado. Consideramos los posicionamientos de dichas iniciativas, las propias dinámicas de rivalidad en el mercado publicitario, de acuerdo a lo que Méndez (2007) ha identificado como fases o etapas de la estructuración capitalista (pp. 221-225). En nuestro período de análisis, nos referimos en un primer momento a la del capitalismo industrial; luego ingresamos en el capitalismo monopolista.

Partimos del supuesto que desde la puesta en circulación de las tres revistas hasta el final de la Gran Guerra (1912-1918), nos encontramos frente a una etapa inicial en la constitución de los mercados publicitarios; en la mayor parte de ella, ninguna de las tres revistas se habría constituido como núcleo fundamental de la colocación de avisos. A partir de la culminación del conflicto bélico y hasta casi las postrimerías de la década de 1920 -en el concierto de crisis del 29', pero también de un marcado ascenso para las actividades industriales y, con ellas, las de la rama farmacéutica argentina- nos hallamos frente a un segundo momento de los mercados publicitarios. Sin lugar a dudas, estos sucesos político-económicos, junto con otros locales, de carácter profesional e 
institucional, terminaron por jalonar fenómenos publicitarios particulares. Finalmente, en una tercera etapa -delimitada entre los últimos años de la década de 1920 y la mayor parte de la siguiente, precisamente hasta el inicio de la Segunda Guerra Mundialhallamos ciertos entramados publicitarios ligados al escenario de competencia que se venía dando desde finales de la Gran Guerra entre los actores extranjeros, especialmente por parte de Francia, Alemania y Estados Unidos. El contexto de rivalidad, propio de las décadas de 1920 y 1930 -junto con el advenimiento de la Industrialización por Sustitución de Importaciones en Argentina- incidió de manera particular en las dinámicas de colocación y el contenido de las publicidades de las iniciativas foráneas y nacionales en el sector farmacéutico y de insumos médicos especializados.

Desde otro enfoque examinamos las publicidades de las iniciativas nacionales y extranjeras estudiando los cambiantes entramados textuales y recursos gráficos que articularon los distintos productores para posicionarse en un mercado competitivo y dirigido a un público concreto. De acuerdo al extenso recorrido histórico de las empresas extranjeras en el mercado especializado (Rodríguez Nozal, 2007) -y, luego de 1918, en un escenario en que era posible ganar terreno tras el cierre de ciertos mercados a productos alemanes- conjeturamos que ellas constituyeron una vanguardia en materia de utilización de recursos gráficos en las publicidades.

Particularmente, un análisis de contenido de los entramados textuales presentes en las publicidades de las iniciativas nacionales nos permitió vislumbrar que muchos de ellos se habrían ido transformando al calor del proceso de desarrollo industrial nacional, marcando una tendencia progresiva -más visible a fines de la década de 1920 y a principios de 1930- a utilizar referencias a lo local y al proceso de industrialización en marcha.

Se propuso un abordaje anclado en una metodología de trabajo fundamentalmente cualitativa (aunque no soslayamos elementos cuantitativos, presentados a través de gráficos), definida a partir de la articulación del análisis histórico hermenéutico y del estudio de contenido, recuperando para este último algunas herramientas que nos otorga la sociosemiótica.

A lo largo de nuestra indagación recurrimos a diversos aportes historiográficos que vienen recuperando los distintos momentos y rasgos del proceso de industrialización en la Argentina. De manera convergente, nos aproximamos a las publicidades a partir de un análisis de contenido, centrado en sus recursos textuales y gráficos buscando identificar y definir tendencias dominantes. Al reconocer estos indicadores revisamos dimensiones del contexto histórico de competencia y consolidación diferencial de las iniciativas que colocaron publicidades en las editoriales. Para la aproximación a los recursos gráficos que se utilizaron en las publicidades bajo estudio, consideramos el uso de color, las ilustraciones, la existencia del logo empresarial, etc. En cuanto a las tramas textuales, nos centramos en un estudio que nos develara las interrelaciones entre los procesos de pugna y afirmación de las iniciativas con los contenidos semánticos históricos que atraviesan los anuncios. 
Dentro de esta segunda vertiente analítica, los aportes teóricos de Eliseo Verón devinieron fundamentales, pues el autor esclarece el concepto de discurso junto con el saldo positivo de su irrupción. Dicho término abre la posibilidad de una reformulación conceptual que da como resultado el surgimiento de la teoría de la discursividad o de los discursos sociales. No obstante, destacamos que además de las herramientas que nos otorga esta teoría, trabajamos con categorías analíticas que remiten a distintos niveles de la lengua, tales como nivel gráfico y gramatical. Partimos de entender, junto con Pessi, que, en el nivel gráfico, el empleo de distintos formatos tipográficos, "destacados" (cursiva, negrita, subrayado, mayúsculas) y de la puntuación (puntos suspensivos, signos de exclamación, comillas, paréntesis) adquieren una relevancia fundamental, en particular, cuando aparecen en forma combinada. "Junto con la imagen, son los encargados de indicar de forma visual la existencia de un sentido paralelo, una lectura en segundo plano o de señalar el camino que debe seguir el lector en la interpretación del mensaje" (Pessi, 2010, p.11). En el nivel gramatical, atendimos a los recursos morfosintácticos de la lengua, tales como la elipsis y construcciones nominales, las construcciones comparativas, los conectores, las fórmulas de tratamiento y el discurso directo (Pessi, 2010, pp. 13-17).

El examen de estos recursos -junto con la teoría de los discursos sociales- nos permitió introducirnos en la lógica de las estrategias discursivas en las publicidades seleccionadas y sus mutaciones conforme a las diferentes etapas en que se suceden las variadas configuraciones de los mercados publicitarios de medicamentos e insumos médicos especializados. Todo esto constituyó en gran medida un ejercicio analítico que se vinculó con el proceso de desarrollo industrial nacional, con los momentos de las referidas dinámicas de consolidación de las elites médicas consideradas, con las transformaciones de la morbi-mortalidad de las poblaciones, en un contexto de pugnas internacionales con gran penetración en los mercados objeto de nuestro estudio.

Se estructuró el escrito a partir de la delimitación de tres períodos referidos anteriormente; cada uno de ellos constituye capítulos extensos, compuestos por secciones demarcadas por los derroteros editoriales de las revistas seleccionadas. El primer momento analítico se desarrolla entre 1912 y 1918 -que se corresponde con el primer capítulo-, años durante los cuales hemos mostrado una situación inicial en la configuración de los mercados de medicamentos e insumos médicos especializados. En dicha sección reconstruimos las estructuras económicas en el plano global y el nacional, los primeros pasos de la industria nacional $-\mathrm{y}$, dentro de ella, la farmacéutica- y las dinámicas publicitarias en las revistas médicas seleccionadas de Córdoba, Rosario y Buenos Aires. En el estudio de cada una de las editoriales ponderamos las condiciones de producción, marcas y huellas textuales, junto con las estrategias discursivas articuladas, tensionando específicamente los niveles gráfico y gramatical.

El segundo capítulo de nuestro trabajo presenta correlación con el período iniciado inmediatamente después a la finalización de la Primera Guerra Mundial, llegando hasta las postrimerías de la década de 1920. Al igual que en la sección anterior, aquí ponemos 
en consideración a cada revista de manera singular, estableciendo ciertos paralelismos entre cada una de ellas a partir de las variables ponderadas.

Finalmente, entre la Gran Depresión y los inicios de la Segunda Guerra Mundial ubicamos el tercer -y último gran capítulo- de nuestro estudio. Continuando con la lógica y subdivisión de los apartados previos, aquí observamos ciertos entramados publicitarios ligados en algunos casos al estancamiento respecto a los momentos anteriores y, en otros, a procesos de consolidación.

\section{Referencias bibliográficas}

Armus, D. (2007). La Ciudad Impura. Salud, Tuberculosis y Cultura en Buenos Aires, 18701950. Buenos Aires: Edhasa.

Armus, D. (2016). Medicina casera, remedios y curanderos en los inicios de la medicalización de la ciudad moderna. Buenos Aires, 1870-1940. Tempos Históricos, 20, 47-80.

Biernat, C. y Simonetto, P. (2017). Provisión pública y oferta privada de medicamentos contra las enfermedades venéreas. Argentina 1930-1945. Revista Ciencias de la Salud, 15(2), 273-291.

Carbonetti, A. (2013). Ofrecimiento de productos en épocas de epidemia. La publicidad en momentos de la pandemia de "gripe española" en Argentina, 1918-1919. En M.A Cuenya y R.E. Urroz (Comps.), Nuevas miradas desde América Latina y México. Enfermedad y control social. Siglos XIX y XX (pp. 147-167). Puebla: Instituto de Ciencias Sociales y Humanidades de la Benemérita Universidad Autónoma de Puebla.

Carbonetti, A. y Sedrán, P. (2018). Curas milagrosas. Publicidades de medicamentos varios en la prensa santafesina (1890-1918). História, Ciências, Saúde-Manguinhos, 26 (4), 1121-1137.

Caro Amela, A. (2008). La publicidad como dispositivo operacional. Pensar la Publicidad. Revista Internacional de Investigaciones Publicitarias, 2 (2), 81-106.

González Leandri, R. (1998). Asociacionismo y representación de intereses médicos en Buenos Aires, 1852-1880. Asclepio, 50 (2), 187-203.

Marafioti, R. (1989). La publicidad, significante del consumo. Cadernos de Estudos Linguísticos, 16, 97-122.

Méndez, R. (2007). Globalización y organización espacial de la actividad económica". En J. González, J. Romero y J. Ortega Valcárcel (Comps.), Geografía Humana. Procesos, riesgos e incertidumbres en un mundo globalizado (pp. 221-271). Barcelona: Ariel.

Millán Barroso, P. J. (2003). Publicidad, retórica y sociedad. Perfiles argumentativos del discurso publicitario. Comunicación: revista Internacional de Comunicación Audiovisual, Publicidad y Estudios Culturales, 2, 115-128.

Pessi, M. S. (2010). Tabú y publicidad. El titular en avisos publicitarios gráficos de productos para el período menstrual (1930-1955). Tonos Digital, 19, 1-27. 
Rodríguez Nozal, R. (2007). Sanidad, farmacia y medicamento industrial durante la II República (1931-1936). Revista de la Sociedad Española de la Historia de las Ciencias y de las Técnicas, 30 (65), 123-150.

Rodríguez, M. L.; Carbonetti, A.; Rizzi, G. y Rivero, D. (2014). El mercado de las publicidades de medicamentos e insumos médicos especializados en el interior de Argentina: El caso de la Revista del Círculo Médico de Córdoba y la Revista Médica de Córdoba, Argentina, 1912-1938. Asclepio, 66 (2), 1-16.

\section{Para citar este resumen:}

Rivero, María Dolores (2021). Resumen de tesis: “Dinámicas publicitarias en materia de aparatología terapéutica y farmacología: una aproximación a los mercados de Córdoba, Rosario y Buenos Aires (1912 - 1938)". Anuario de la Escuela de Historia Virtual, $19,150-156$. 